\title{
Explaining Education Level and Internet Penetration by Economic Reasoning - Worldwide Analysis from 2000 through 2010
}

\author{
Halit Ünver \\ University of Ulm, Germany
}

\begin{abstract}
A main intention is to investigate the digital inequality regarding education level and Internet access between different countries with empirical methods and (multivariate) regression analysis using linear and non-linear functions. The UN education index and adult literacy rate are used to measure the education level. Internet penetration rate gives the number of Internet users per 100 inhabitants. There is an empirical positive relation between education level and Internet penetration in a country. The degree of relation between education index and Internet penetration rate is higher than the degree of relation between adult literacy rate and Internet penetration rate. We not only demonstrate these trends but are also able to explain them to a great extent by identifying the relation of the different parameters studied with the income situation in countries. The results show, that GDP per capita drives primarily the Internet penetration rate and even gains in importance between 2000 and 2010, if the education level is expressed via the education index. But the role of GDP per capita remains at the same level over time, if education is measured via adult literacy rate. This study concludes, that the digital divide is declining over the decade between 2000 and 2010, since more people worldwide use the Internet, but a high digital inequality explained to a significant extent by the relation between Internet penetration, education level and average income still exists. This study argues that policymakers need to promote comprehensive literacy education.
\end{abstract}

\section{Introduction}

A key performance indicator to lead a fulfilled and successful life is education, especially in times of globalization. Information and communication technology (ICT), especially the Internet, is a main driver of globalization processes in economical, political and social respect [31]. It has advanced very fast throughout the world and one main reason for this is, that computing power per unit cost doubles every 18-24 month (so-called Moore's law) [23]. With information and communication technology not only driving globalization, but also education processes and economic progress and with a better education and higher income driving the use of ICT, the question is for the detailed relationship between these phenomena. When trying to answer this basic question, it is necessary, however, to keep in mind, that in the past the status of a single computer and of many computers in a network was not the same all over the world than today, especially in an educational sense. The so-called post-Gutenbergian era is very closely coupled with the beginning of the history of computers. Historically, computers themselves have transformed from a calculating machine into a 'writing-down-system', involving powerful new text operations like searching, sorting, correcting, formatting, desktop publishing of any written text, simply transforming the computer into a text and language processing machine [7]. One of the most important differences between the pre- and post-Gutenbergian era is the non-linear reading style with hypertext, already in place before the establishment of the World Wide Web (www). In 1990 Tim Berner-Lee created the first web server, a client with a browser and editor, and the first few websites. The www gives the Internet a graphical user interface (GUI) through which it has become a mass-medium, although it was a network only for military and universities in the US at first.

The way towards an information society [32] was primarily done by mobile phone subscriptions and its rapid growth, also known as the ICT 'miracle', which is basically induced by the introduction of prepaid systems. Today more than $70 \%$ of all mobile-cellular subscriptions are prepaid (and as many as $87 \%$ in developing countries) [18]. The spreading of Internet subscriptions around the world does not have the same speed as the spread of mobile phones, but it is much more important in terms of information acquisition and knowledge enhancement, as it transforms the industrial society into information and knowledge based society. The term 'big data' is actually being used to describe and shape a world, in which the availability and use of huge amounts of data in different areas of our society changes many value added processes, also processes that are related to education [39]. The use of big data is possible, because of the inexpensive computer memory, powerful processors, smart algorithms, clever software, and math that borrows from basic statistics [8]. The Internet is now important as a part of the daily life as well as a mean for defining the technological development status of a country. The convergence of mobile phone technologies and the Internet [24] into mobile Internet access, e.g. via smartphones, will further accelerate the spreading speed of mobile phones and the social importance of 
the Internet, also with respect to knowledge enhancement and education.

\section{Background}

Indeed, one of the most important terms in the field of information society is 'digital divide'. It was high on the agenda of the European Union in [32], the 'German Forum Information Society' [12] of the federal government, and a topic of the World Summit on the Information Society (WSIS) took place in Geneva in 2003 [42] and Tunis in 2005 [43] as well as at the World Summit on Sustainable Development (WSSD) in Johannesburg [44]. The Research Institute for Applied Knowledge Processing (FAW) in Ulm was involved in all these processes.

The Internet is a showpiece of the worldwide technological era and network society [10]. Today it provides a very effective and efficient way of communicating with minimal constraints in time and distance all over the world [35]. The Internet infrastructure has many physical and logical layers [OSI, 1994]. As we know, good infrastructure (traffic infrastructure, technological infrastructure, housing infrastructure, energy infrastructure etc.) is one of the most important ingredients of wealth [33]. Highest and high developed countries did develop their communication infrastructure earlier and much more extensively, than low and lowest developed countries, because they could and can invest more capital into it, which results in higher penetration rates to the Internet [5]. Actually high developed countries are investing into broadband access. For example, the 'Education for All' programme is driven by the broadband commission of international organizations [Broadband Commission, 2013]. In 2000 only the US (4:4\%) and Korea (30:3\%) had broadband access. However, the worldwide fixedbroadband penetration rate is $7: 6 \%$ in 2010 . The technological convergence of the Internet and mobile phone leads to mobile Internet access, also called mobile broadband [18]. The global mobile broadband penetration rate is $11: 3 \%$ in 2010 and approx. ten times higher in developed countries $(42: 9 \%)$ than in developing countries $(4: 4 \%)$. This rate increased up to $29: 5 \%$ in 2013 , but that year is out of the focus of this study.

On the other hand developing countries can leapfrog [34] technological developments. Africa has more mobile phone subscriptions today than fixedline subscriptions (PSTN) and 4 billion people now have a mobile phone subscription worldwide. According to the fact that many infrastructural components are very low developed in Africa, mobile phones are a fundamental tool to generate wealth in these countries. The payment process via mobile phones in Kenia is a good example for that [40]. Obviously, all these developments could have a positive influence to educational processes in countries.

One quantitative method for measuring the technological development, in terms of the Internet, is to measure the percentage of a population using the Internet while ignoring the type of access (private/ shared), connection (wired/wireless) or location (household, school, office, cafe etc.) involved. The Internet penetration rate (IPR) is the estimated number of Internet users out of a total population. This includes those using the Internet from any device (including mobile phones) over the last 12 months, measured through household surveys. If household surveys are not available, an estimate can be derived based on the number of Internet subscriptions [18].

Many efforts were undertaken to measure the education level of a country's population. Indices like the adult literacy rate, gross enrollment ratio, as well as expected and mean years of schooling, measure the education level in different ways and are used in different situations. The adult literacy rate is the percentage of the population age 15 and above who can read and write a short, simple statement (with understanding) concerning their everyday life [36]. Generally, literacy also encompasses numeracy, the ability to make simple arithmetic calculations like adding numbers. This indicator is calculated by dividing the number of literates aged 15 years and over by the corresponding age group population and multiplying the result by 100 . Due to the fact that literacy is a main feature to use the Internet, initially this index is used to analyze the relation between education level and Internet penetration in this study.

The UN education index instead is measured by the mean of years of schooling for adults aged 25 years and more and expected years of schooling for children of school entering age. Mean years of schooling is estimated based on educational attainment data from censuses and surveys available in the UNESCO institute for statistics [38]. Expected years of schooling estimates are based on enrollment by age at all levels of education and population of official school age for each level of education. Expected years of schooling are capped at 18 years. The indicators are normalized using a minimum value of zero, while maximum values are set to the actual observed maximum value of mean years of schooling from the respective countries in the time series 1980-2012. For example, 13.3 years are estimated in this context for the United States in 2010. Expected years of schooling are maximized by its cap at 18 years. The education index is a subindex of the human development index (HDI), which is reported in the Human Development Report [16]. The education index is used to analyze the relation between education level and Internet penetration with a more detailed index regarding education level compared to the adult literacy rate. 


\section{Literature Review}

In the 1990s, the term digital divide emerged to describe technology haves and have-nots. Current research regarding digital divide has a descriptive character. Those studies describe the digital divide by using demographical, economical or educational data, in general at an individual level of Internet usage or digital skills of people in a country [9]. This study investigates the digital divide more from the perspective of digital inequality and from an educational perspective from 2000 through 2010.

If we look at the history of the digital divide in general, there are mainly four successive kinds of access in the appropriation of digital technology [11]. These kinds of access are a) motivation, b) physical and material access, c) digital skills and d) digital usage. In this research study the focus is on access types b) and c) by searching for empirical relations between the education level and Internet penetration rate of countries. It is assumed that the digital skills of a society are higher if the education level of this society is higher. Physical and material access corresponds to Internet penetration.

In the past, studies about using technology acceptance explain, how attitudes determine Internet penetration. Such studies show, that some of the faster rates of growth in Internet use have been among individuals who are older, less educated, of minority status or with lower incomes. However, Internet Usage rates associated with these demographic groups are lower than that of the general population [28]. Another study points out, that more educated people use the Internet more actively and their use is more information oriented, whereas the less educated seem to be interested particularly in the entertainment functions of the Internet [4].

A similar research work to this study examines the relation of the Internet penetration rate with the human development level over the decade from 2000 through 2010 [29]. These results support the argument that a digital divide exists between developed and developing countries. The main outcomes of this study are that there is a positive correlation between human development level and Internet penetration rate and that the correlation has become slightly stronger from 2000 through 2010 . As well, that study concludes higher growth rates of Internet penetration in developing countries than in developed countries. This corresponds in a certain way again to the so-called leapfrogging effect [34]. Another finding is, that the Internet penetration rate of countries with a higher change in the human development level tends to grow somewhat slower than in countries with lower change in human development. If we look to the digital divide with respect to Internet penetration, there is still an inequality between developed and developing countries [29]. Our study suggests, however, that this phenomenon tended to be stronger during the past decade.

A number of empirical studies have been done on the topic of digital divide. A few of them highlighted that income level [1] [2], income distribution [14] [45], education level [15], [21], size of population [30] and urbanization [3] have essential correlation with Internet penetration levels of countries.

Andres et al. [2] stated, that low-income countries have a steeper Internet diffusion curve than that of high-income countries. Although this result is rational, because low-income countries can leapfrog technological developments, it has to be mentioned, that the distinction to only two categories of income levels is questionable, because this collapsed the four income groups of the World Bank classification. Zhang found out a positive contribution of GDP per capita (PPP, current int.\$) to Internet penetration and a negative influence of income distribution measured by the Gini-Index. Here it should be noted, that a higher average income corresponds to a more equal income distribution in general [20] and that's not discussed anyway in the results of Zhang. Furthermore he did not explain the relation between GDP per capita and Internet penetration in form of a detailed function. Hargittai demonstrated that the education level and the English proficiency improved the model for the Internet hosts penetration levels across countries. Kiiski et. al. [21] showed that the average years of schooling is considerably a positive factor for the Internet hosts per capita in a country. Even so another study find out that the degree to which the difference in Internet rates depends upon education level is surprisingly small [5]. This contradicts our findings.

However, there seems to be no related scientific work analyzing the empirical relation between education index and Internet penetration, especially over the decade from 2000 through 2010. Therefore, this issue is tackled in this study. Furthermore, most of the related work describes the relation between economical development, education level and Internet penetration with linear regression functions and with logarithmic or exponential functions. In this study, non-linear regression models like the logistic function or functions according to Planck's law are also used to describe the relation between the different parameters. Specifically the multivariate regression analysis for the relation between the Internet penetration rate as the dependent and education level and income situation as the different independent variables, which have been described by non-linear regression functions, is a contribution to the scientific field related to digital divide or digital inequality. 


\section{Data Collection and Empirical Analysis}

Internet penetration rates (IPR) are available (free of charge) on the International Telecommunication Union website [19], where also some other ICT key indicators can be downloaded. Data for measuring the education level of a country and its population can be downloaded from the statistical division of the UNESCO website [37] and UN Development Programme [UNDP, 2013] websites. On those websites data is available for national adult/youth literacy rates, enrolment ratios and education index by international standard classification of education level (ISCED). This study focuses on adult literacy rate and education index. Due to the lack of data regarding adult literacy rate for many developed and developing countries, polynomial interpolation is used to have enough data for pair-by-pair comparison concerning Internet penetration rate. The World Bank provides data regarding the economic development level of countries [41].

The earliest data available for the Internet penetration rate as a percentage of individuals using the Internet out of a country's total population, is for 2000 and the latest for year 2012, whereby this study examines data only until 2010 to monitor the change in a decade. The year 2000 suits also historically well for the analysis of the beginning of the Internet usage dissemination. In 2000 there have been two historical events, one known as 'millennium bug', which describes the critical keys to succeed in tackling the year 2000 (2YK) [6] and the other one called 'dotcom-bust', which concerns the dotcom bubble and a corresponding (temporal) investment disaster [25]. These historical events are two signaling occurrences on the route towards a global information society.

IBM SPSS Statistics 20 software package is used in this study. It is an integrated family of products that addresses the entire analytical process, from planning to data collection to analysis, reporting and deployment. Regression is used to model the relation between education level as the independent variable and the Internet penetration rate as the dependent variable. Also the income level by means of GDP per Capita (PPP) is used as the independent variable to find plausible explanations for the results regarding the relation between education level and Internet penetration. Correlation quantifies the degree to which two variables are related, and this regards a linear form of mutual dependency [27]. Regression finds the best line or function (method of least squares), here from a given class of functions, with a number of parameters, which predict the dependent variable from the independent variable [13]. In this study linear and non-linear regression functions, as represented in Table 1, are used to model the relation between the dependent and the independent variables.

Table 1: Linear and Non-Linear Regression Functions Used

\begin{tabular}{|l|l|}
\hline Function & Formular \\
\hline Linear & $y_{\mathrm{i}}=\mathrm{a}+\mathrm{b} \cdot x_{\mathrm{i}}+\varepsilon_{\mathrm{i}}$ \\
\hline Exponential & $y_{\mathrm{i}}=\mathrm{a}+\mathrm{b} \cdot \exp ^{\left(c x_{\mathrm{i}}-\mathrm{d}\right)}+\varepsilon_{\mathrm{i}}$ \\
\hline Logarithmic & $y_{\mathrm{i}}=\mathrm{a}+\mathrm{b} \cdot \log \left(x_{\mathrm{i}}-c\right)+\varepsilon_{\mathrm{i}}$ \\
\hline Logistic & $y_{\mathrm{i}}=\frac{\mathrm{a}+c \cdot \exp ^{d \cdot x_{\mathrm{i}}}}{}+\varepsilon_{\mathrm{i}}$ \\
\hline Planck's Law & $y_{\mathrm{i}}=\frac{\mathrm{a} \cdot x_{\mathrm{i}}^{\mathrm{c}}}{c \cdot \exp ^{d \cdot x_{\mathrm{i}}-1}}+\varepsilon_{\mathrm{i}}$ \\
\hline
\end{tabular}

The function which fits most to the data by means of method of least squares is then finally used for the relation between the dependent and independent variable in a certain year. Reasons for using these functions are as follows:

1. Linear functions are easy and one of the first approach, if humans try to understand real-life phenomena with given data.

2. Exponential functions are often used to represent growth and decay, like population growth or depreciations

3. Logarithmic functions are commonplace in scientific formulae, and in measurements of the complexity of algorithms and in many other different applications like in the measurement of earthquakes and sound

4. Logistic functions are used to model reallife quantities whose growth levels off because the rate of growth changes, from an increasing growth rate to a decreasing growth rate.

5. Planck's law describes originally the electromagnetic radiation emitted by a black body in thermal equilibrium at a definite temperature. Anyway, in general, it decribes an initial increase of the dependent variable at higher levels of the independent variable, and then a decrease of the dependent variable at higher levels of the independent variable.

Surely, more functions like higher degree polynomials could be analyzed in detail to fit the data best, and with enough rich classes, every data can almost precisely be reproduced, however in a way that has no mean from a practical sense. So, only relative simple and smooth functions make sense. The functions above are widest known and implemented in the used tools. Obviously they are sufficient in our case, if one looks to the relation between the dependent and independent variable via 
a scattered plot and the position of data. Regression analysis do not represent a trying to understand the reasons (causality) behind how the world works, it represents the learning about an association among phenomena and using that knowledge to get things done [8].

\section{Relation between Education Level and Internet Penetration}

In a first reflection it seems natural, that a positive relation exists between the education level of a country and the Internet usage respectively Internet penetration in a country. It is reasonable to assume, that illiterate people cannot use the Internet to an extent like literate people and not nearly to an extent like high educated people. Nevertheless a detailed cross-country empirical analysis of these phenomena is of peculiar interest for the decade between 2000 and 2010 .

\subsection{Internet Penetration and Education Level expressed via Adult Literacy in 2000 and 2010}

The first step towards a higher education is the ability to read and write, why this feature of the population in a country is being considered in this study initially. It is also known, that digital skills of people determine the quality of their Internet usage and that digital skills are also driven by literacy first of all.

The global adult literacy rate grew from $76 \%$ in 1990 to $81 \%$ in 2000 , while $75 \%$ of illiterate adults are concentrated in ten countries (India, China, Pakistan, Bangladesh, Nigeria, Ethiopia, Egypt, Brazil, Indonesia and Dom. Rep. of Congo). In 2000 there were (only) about 400 million people using the Internet out of the then 6.1 billion total world population. This corresponds to a world Internet penetration rate of $6.55 \%$. At that time the four countries USA, Japan, Germany and China represent approximately $50 \%$ of the worldwide Internet users.

Regarding the relation between the adult literacy rate (ALR) and the Internet penetration rate (IPR), following Table 2 shows the descriptive statistic, i.e. number of data $(\mathrm{N})$, spread (max. value minus min. value), minimum value (Min), maximum value (Max), mean value (Mean) and standard deviation (Std.) for the two parameters in the year 2000. The mean value of $8.06 \%$ for the Internet penetration rate is higher than the above mentioned $6.55 \%$, because for reasons of data gaps, only 160 countries are considered in this analysis out of almost 240 countries registered at the ITU ${ }^{1}$. It can be seen a maximum value of $52 \%$ for the Internet penetration rate, which was achieved in Canada and Norway. The countries Australia, Denmark, Finland,
Iceland, Korea Rep., Netherlands, New Zealand, Sweden, Switzerland and United States have all an IPR between $40 \%$ and $50 \%$ in 2000. Remarkable 69 countries out of total 160 countries analyzed (43\%), most of them are African states and India, have less than $1 \%$ Internet penetration rate in 2000. The minimum value of $9.54 \%$ for ALR is in Niger. If we look to the ALR equals $50 \%$ or less, we observe again countries from Africa and the states Bangladesh, Nepal and Pakistan.

Table 2: Descriptive Statistics Adult Literacy (ALR) and Internet Penetration (IPR) 2000

\begin{tabular}{|l|l|l|l|l|l|l|}
\hline 2000 & N & Spread & Min & Max & Mean & Std \\
\hline ALR & 160 & 90.25 & 9.54 & 99.79 & 81.34 & 21.19 \\
\hline IPR & 160 & 51.99 & 0.01 & 52.00 & 8.06 & 13.12 \\
\hline
\end{tabular}

As mentioned before, the Internet usage spreading is not able to keep up the 'mobile miracle' speed, but the variety of applications in the Internet is on the other hand much more suitable for daily use, so the spread will eventually continue. In 2010 the world Internet penetration rate was about $30 \%$, which means 2 billion Internet users out of 6.8 billion people all over the world. The four counties USA, Japan, Germany and China had together approximately 850 million Internet users, where China had the biggest growth and countries like Burundi, Congo Dem. Rep., Ethiopia, Eritrea, Niger, Myanmar, Sierra-Leone, and Timor-Leste have still an IPR less than $1 \%$ since 2000.

The global adult literacy rate is about $84 \%$ in 2010. The lowest literacy rates are observed in subSaharan Africa and in South and West Asia. Adult literacy rates were below $50 \%$ in the following 11 countries: Benin, Burkina Faso, Chad, Ethiopia, Guinea, Haiti, Liberia, Mali, Niger, Senegal and Sierra Leone. In Central and Eastern Europe, Central Asia, East Asia and the Pacific, and Latin America and the Caribbean, the average adult literacy rates were greater than $90 \%$. The maximum value of $93 \%$ regarding ALR is achieved in Norway and Iceland. Norway is again at the top of the list as in the year 2000. The minimum value of $30.75 \%$ for ALR is in Niger, which is again that country, where the relatively highest value of illiterates lives. In Brazil, China, Indonesia, and Mexico the adult literacy rate exceeded $90 \%$ and this is a good sign compared to other (big) developing countries. Table 3 gives the relevant descriptive statistics for adult literacy rate (ALR) and Internet penetration rate (IPR) for the year 2010.

The mean value of $34.68 \%$ for the Internet penetration is higher than the above mentioned $30 \%$, because only 167 countries are considered in this study out of almost 240 countries registered at the ITU. Morocco is an interesting case, because both, the ALR and IPR have approximately the same value

${ }^{1}$ Small states, islands and countries where no data is available are not considered 
of $57 \%$ and $52 \%$, respectively. It is reasonable to say, that nearly everybody in Morocco who is able to read and write used the Internet in 2010. This is a good example for the potential limitation of the IPR.

Table 3: Descriptive Statistics Adult Literacy (ALR) and Internet Penetration (IPR) 2010

\begin{tabular}{|l|l|l|l|l|l|l|}
\hline 2010 & N & Spread & Min & Max & Mean & Std \\
\hline ALR & 167 & 71.22 & 28.70 & 99.92 & 84.04 & 18.24 \\
\hline IPR & 167 & 93.18 & 0.21 & 93.39 & 34.68 & 26.93 \\
\hline
\end{tabular}

Table 4: $L S E$ and $R^{2}$ for Regression $I P R=f(A L R)$

\begin{tabular}{|l|l|l|l|l|}
\hline & \multicolumn{2}{|c|}{2000} & \multicolumn{2}{c|}{$\mathbf{2 0 1 0}$} \\
\hline & LSE & $\boldsymbol{R}^{2}$ & LSE & $\boldsymbol{R}^{\mathbf{2}}$ \\
\hline Linear & 22183 & 0.190 & 72574 & 0.420 \\
\hline Exponential 1 & 22742 & 0.170 & 57252 & 0.542 \\
\hline Exponential 2 & 20543 & 0.250 & 56620 & 0.547 \\
\hline
\end{tabular}
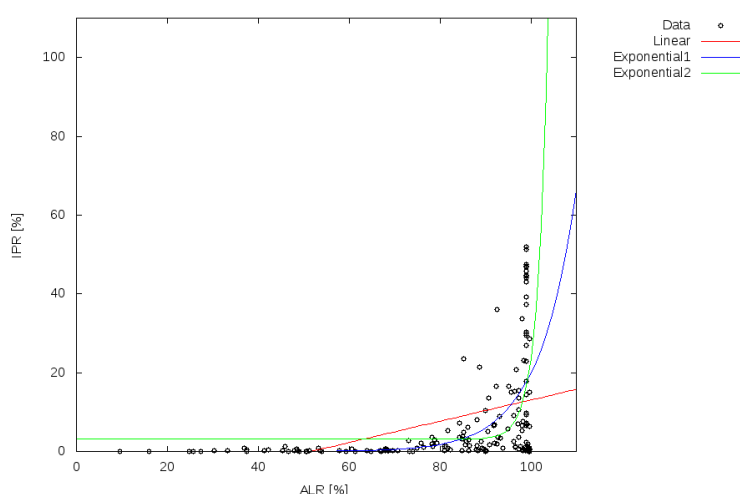

(a) 2000

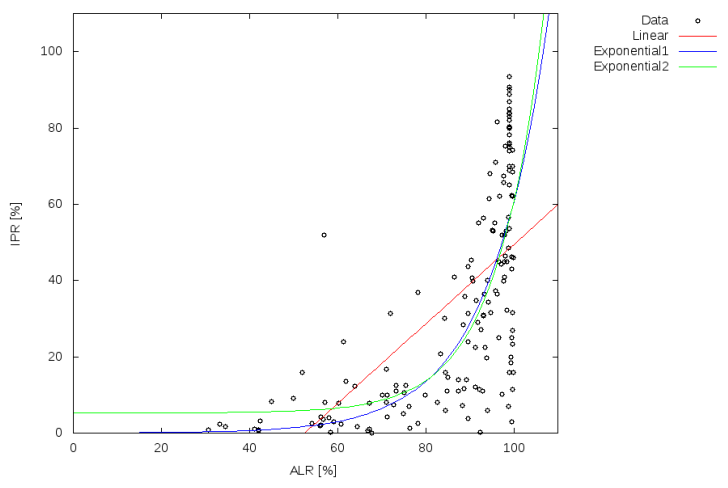

(b) 2010

Figure 1: Internet Penetration (IPR) as function of Adult Literacy (ALR), Year 2000 (a) and 2010 (b)

Concerning adult literacy rate (ALR) and Internet penetration rate (IPR) following Figure 1 shows the relation between both indices for the year 2000 (a) and 2010 (b) with a scattered plot. One linear and two different exponential regression functions, one with an offset and another without, are used to model the relation. The exponential regression function with an offset fits better to the optimization condition (least square method) in comparison to the other predefined regression functions. With reference to the least square optimization, the following Table 4 gives the number for the least square error (LSE) and coefficient of determination $\left(\mathrm{R}^{2}\right)$ for the linear and two exponential regressions.

It can be concluded, that the linear model describes the relation between the adult literacy rate and Internet penetration rate in 2010 better than the linear regression in 2000, but not good enough. The computations yield, that the exponential regression model fits the data best in 2000 and 2010, namely the 'Exponential2' regression model with an offset. So far it can be said, that a high adult literacy does not force a high value in Internet penetration. Some other factors, which will be analyzed below, must influence a high value in Internet penetration. But a high adult literacy rate is necessary to achieve a high Internet penetration in a country in 2000. A low value of adult literacy is in fact statistically an indicator for a low value of Internet penetration, which seems also natural.

\subsection{Internet Penetration and Education Level expressed via Education Index}

Once someone can read and write, the next step is to strive for a long school education and having a university degree, if a person wants to be well educated. It is also known, that the digital skills of people with higher education or university degree are higher on average than that one of the lower educated people. Consequently their Internet usage is in terms of knowledge acquisition with a higher quality.

As mentioned above, the education index describes the education level of a country with better quality than the adult literacy rate, why this study uses it, to examine the relation between education level and Internet penetration more detailed. The education index has a mean value of 0.6 in 2000 . Table 5 shows, in analogy to Table 2, the relevant values for the education index (EI) and the Internet penetration rate (IPR) for the year 2000.

The mean value of $8.84 \%$ for the IPR is, again, higher than the above mentioned mean value of the worldwide IPR, because for reasons of data gaps only 146 countries are considered here. The minimum value of 0.11 for the EI is in Niger and it is not surprising that this country is at the bottom of the list, because it is also the country with the lowest adult literacy rate in 2000 .

Table 5: Descriptive Statistics Education Index (EI) and Internet Penetration (IPR) 2000

\begin{tabular}{|l|l|l|l|l|l|l|}
\hline 2000 & N & Spread & Min & Max & Mean & Std \\
\hline EI & 146 & 0.86 & 0.11 & 0.97 & 0.59 & 0.21 \\
\hline IPR & 146 & 49.99 & 0.01 & 51.99 & 8.84 & $\begin{array}{l}13.5 \\
8\end{array}$ \\
\hline
\end{tabular}


As we know, a higher illiteracy rate in a country results in a lower school enrollment ratio and vice versa. But this interdependency is out of scope in this study.

Table 6: Descriptive Statistics Education Index (EI) and Internet Penetration (IPR) 2010

\begin{tabular}{|l|l|l|l|l|l|l|}
\hline 2010 & N & Spread & Min & Max & Mean & Std \\
\hline EI & 167 & 0.80 & 0.18 & 0.99 & 0.64 & 0.20 \\
\hline IPR & 167 & 94.80 & 0.21 & 0.95 & 33.22 & 27.59 \\
\hline
\end{tabular}

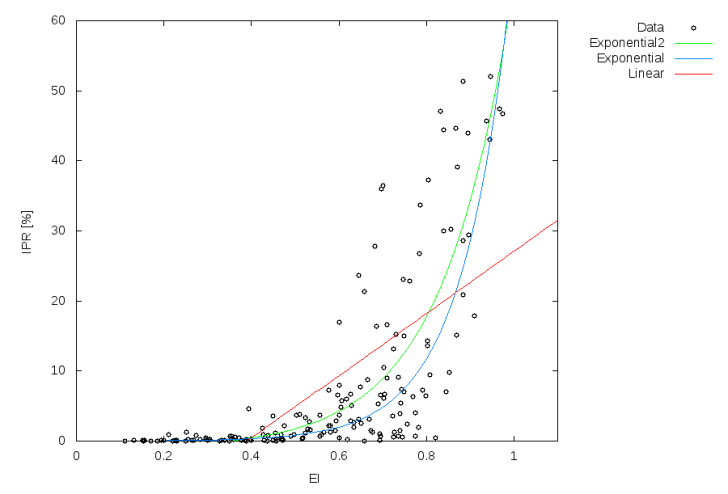

(a) 2000

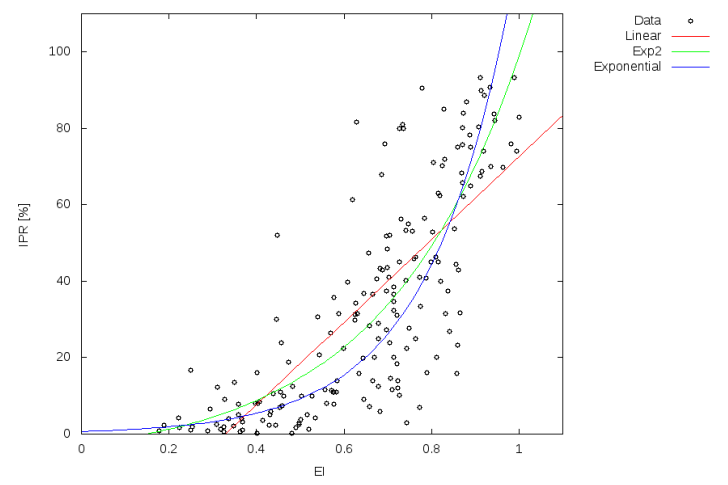

(b) 2010

Figure 2: Internet Penetration (IPR) as function of Education Index (EI), Year 2000 (a) and 2010 (b)

Approximately $47 \%$ of the countries analyzed have a lower EI as the mean value of 0.59 and a very high EI of 0.8 and more is achieved in some European countries (Belgium, Czech Rep., Denmark, Finland, France, Germany, Hungary, Ireland, Netherlands, Spain, Sweden) and in Australia, Canada, Israel, Japan, Korea, New Zealand and United States. The education index has a mean value of 0.64 in 2010. Table 6 gives the descriptive statistics for the year 2010 .

Regarding education index (EI) and Internet penetration rate (IPR) the following scatter plots in Figure 2 show the relation between both indices for the years 2000 (a) and 2010 (b). A linear and two exponential regression functions are used to model the relation between the education index and Internet penetration rate.
Concerning the least square optimization, the following Table 7 gives the numbers for the least square error (LSE) and coefficient of determination $\left(\mathrm{R}^{2}\right)$ for the linear and two exponential regressions for the year 2000 and 2010.

Table 7: LSE and $R^{2}$ for Regression IPR $=f(E I)$

\begin{tabular}{|l|l|l|l|l|}
\hline & \multicolumn{2}{|c|}{$\mathbf{2 0 0 0}$} & \multicolumn{2}{c|}{2010} \\
\hline & LSE & $\boldsymbol{R}^{2}$ & LSE & $\boldsymbol{R}^{\mathbf{2}}$ \\
\hline Linear & 14477 & 0.459 & 47145 & 0.627 \\
\hline $\begin{array}{l}\text { Exponential } \\
\mathbf{1}\end{array}$ & 8109 & 0.697 & 39432 & 0.688 \\
\hline $\begin{array}{l}\text { Exponential } \\
\mathbf{2}\end{array}$ & 8066 & 0.698 & 39078 & 0.691 \\
\hline
\end{tabular}

It is important to note, that countries with an EI of 0.59 (mean value) and lower have all a low IPR, i.e. lower than the worldwide mean value of $8.84 \%$ for the IPR in 2000. Summing up we can say, that the relation between EI and IPR in 2000 is positive and a high EI (EI > 0.8) not grants automatically a high IPR, but all countries with a relative high IPR $(40 \%$ $<$ IPR $<50 \%$ ), i.e. obviously above-average value, corresponds with a high EI. The relation between the EI and IPR for the year 2000 and 2010 is described by a linear and two exponential regression functions. Although the 'Exponential2' model explains this relation better than the 'Exponential1' model, it must be mentioned, that the difference in the values of least square error (LSE) and coefficient of determination between the three functions became smaller in 2010 compared to the year 2000.

\subsection{Summary for the Relation between Education Level and Internet Penetration}

The statistical analysis given convincingly shows that indeed education level either expressed via adult literacy rate or expressed via education index gives clear indications towards Internet penetration. So up to now, this study confirms the positive relation between the education level and the Internet penetration. It shows similar results as other studies in this field of work, however, there seems to be no related work analyzing the two indicators adult literacy rate and education index in detail with linear and non-linear regression functions and a worldwide context, in particular over the decade between 2000 and 2010 .

In looking to all kind of relations analyzed, one has to keep in mind that only about one third of the world population uses the Internet in 2010, two thirds do not. This study would reveal no relation between the education level and Internet penetration rate, if the total world population would use the Internet. If one looking only at very high educated people, such as engineers or natural scientists with 
doctor degree, all of them would probably use the Internet in one form or another, but their number is so small, that it cannot explain nationwide trends. So we have to study larger groups of populations like nations and those educated or not, which show quite different levels of Internet penetration. This is what we do in this paper.

Obviously, the better people are educated, the more they statistically use the Internet. In other words, if somebody is illiterate, it is clear that this person cannot use the Internet to an extent like somebody else, who is able to read and write. The results show, that a high education index reveals more information about good education than the adult literacy rate does, so it is not surprising that high levels of education index even stronger result in a high Internet penetration than high levels of adult literacy rate.

The regression analysis regarding the relation between the adult literacy rate and Internet penetration rate for the decade from 2000 through 2010 yields, that a high value in adult literacy rate is necessary to achieve a high value in Internet penetration, while this fact is more important in 2000 than in 2010. This relation is modelled via an exponential function in both years. The worldwide increase in average adult literacy rate and Internet penetration rate is a positive note.

The analysis for the relation between education index and Internet penetration result in somewhat similar outcome as for adult literacy rate, but with the difference that the dispersion of data is for education index higher than for adult literacy rate. Again, the relation can be modelled via an exponential regression function better than via a linear regression, but the linear model suits also well for the relation between education index and Internet penetration rate in 2010 .

\section{Plausible explanations for the Relation between Education Level and Internet Penetration}

Given that the Internet has revolutionized the amount of available data and is still changing communication and information processes of societies, whereas it also impacts economic, social and cultural development of a country, it is increasingly important to understand which primary factors drive the interaction between the Internet penetration rate and education level. For this purpose, a detailed worldwide analysis of this interaction will be done now. The results obtained so far concerning the interplay of education and Internet penetration are plausible statistical effects. They might express real-life dependencies, but they might also be data artefacts (spurious correlation).
Therefore, we next try to give a real-life explanation for the phenomena observed.

Our main thesis is that there is a third key variable beside the level of education and level of Internet usage that explains to a huge extent the relations observed. Surely, there are more variables like urbanization or population size, which can explain the relation, but to concentrate on main factors they are out of focus here. It is assumed, that the financial situation of people is the main driver for the relations observed. Here, to make things easy, the financial side is represented by the average income in a country, measured by GDP per capita with power purchasing party (PPP). We expect a strong influence of average income on education level in the sense higher income corresponds to higher education level. We expect, that this influence is stronger for the education index than for the adult literacy rate, explaining also this aspect of the statistical relations observed. At the same time, we expect a strong influence of average income on Internet penetration rate. Increasing income would thus promote education level as well as Internet penetration and by this explain to a great extent the relations observed. The following statistical analyses show exactly these effects. We then will do a multivariate statistical analysis using both or even three indicators, namely average income measured by GDP per capita (PPP) and education level, either expressed via adult literacy or via education index, to explain Internet penetration. By doing the multivariate regression, we will get a better feeling concerning the relative power of explanation of the Internet penetration rate by either average income or education level. We expect the stronger explanation power with average income. And we guess that this is even clearer for the education index than for the adult literacy rate.

\subsection{Economic Development and Internet Penetration}

The GDP is a measure of the economical output of a country in terms of products and services in a certain year and is one of the primary indicators of a country's economic performance. GDP per capita divides the total GDP by the number of people in the country, which is especially useful when comparing countries, because it shows the relative performance of countries ${ }^{2}$. A rise in per capita GDP signals growth in the economy and tends to translate as an increase in productivity.

Table 8 gives an overview of the relevant values for the GDP per capita (GDPpC) based on purchasing power parity (PPP) and the Internet penetration rate (IPR) for the year 2000. PPP is gross domestic product converted to international dollars (int. \$) using purchasing power parity rates. An international dollar has the same purchasing power

\footnotetext{
${ }^{2}$ It must be noted that the data for GDP per capita should be regarded with caution. The national accounting systems of each country are far from being of the same quality, some figures even lack reliability. Further to that, the average GDP per capita do not reveal anything about the distribution of the total GDP within the countries.
} 
over GDP as the US dollar (US \$) has in the United States.

Table 8: Descriptive Statistics GDPpC and IPR 2000

\begin{tabular}{|l|l|l|l|l|l|l|}
\hline $\mathbf{2 0 0 0}$ & $\mathbf{N}$ & $\begin{array}{l}\text { Sprea } \\
\text { d }\end{array}$ & Min & Max & Mean & Std \\
\hline $\begin{array}{l}\text { GDPp } \\
\text { C }\end{array}$ & 182 & 90741 & 271 & 91012 & 10975 & 14268 \\
\hline IPR & 182 & 51.99 & 0.01 & 52.00 & 7.91 & 12.73 \\
\hline
\end{tabular}

The mean value for GDP per capita is 10975 (int.\$) for year 2000. Exactly 130 countries out of total 182 considered have a below-average value in their GDP per capita. The descriptive statistic values for the Internet penetration rate have been discussed above, but keep in mind, that we are considering a bit more countries due to reasons of data availability now.

Looking to the GDP per capita and Internet penetration rate in the year 2010, it hast to be mentioned, that the Nordic countries has an average Internet penetration rate of $90 \%$, compared to the world average of about $30 \%$, whereby this region is also at the top of the average income level. Only three countries (Cuba, Equatorial Guinea and Kazakhstan) have an above-average GDP per capita, while they have a below-average Internet penetration rate. All countries, which had this situation in the year 2000, improved their Internet connectivity level to an extent that is acceptable to their above-average income level. Table 9 gives the major descriptive statistics for GDP per capita (GDPpC) and Internet penetration rate (IPR) for the year 2010. The average income increased about 5500 (int. \$) up to 16595 (int. \$), whereas the minimum value of 408 (int. \$) is in the Dem. Rep. of Congo and the maximum value of 126038 (int. \$) in Qatar.

Table 9: Descriptive Statistics GDPpC and IPR 2010

\begin{tabular}{|l|l|l|l|l|l|l|}
\hline 2010 & N & Spread & Min & Max & Mean & Std \\
\hline GDPpC & 183 & 125630 & 408 & 126038 & 16595 & 19233 \\
\hline IPR & 183 & 93.18 & 0.21 & 93.39 & 33.54 & 27.46 \\
\hline
\end{tabular}

The two scattered plots in Figure 3 demonstrate the relationship between GDP per capita (GDPpC, PPP) and Internet penetration rate (IPR) in 2000 and 2010 using linear, logistic, logarithmic regression functions and two different functions according to Planck's law. In year 2000 there are three different Planck functions only for demonstration. As we see in Table 10, the function applicable to Planck fits most to the data, because some countries (Brunei, Kuwait, United Arab Emirates and Qatar) with very high GDP per capita have relatively low Internet penetration rates, which bents the curve concave downwards.
Table 10: LSE and $\mathrm{R}^{2}$ for Regression IPR = $\mathrm{f}(\mathrm{GDPpC})$

\begin{tabular}{|l|l|l|l|l|}
\hline & \multicolumn{2}{|c|}{$\mathbf{2 0 0 0}$} & \multicolumn{2}{c|}{$\mathbf{2 0 1 0}$} \\
\hline & LSE & $\boldsymbol{R}^{\mathbf{2}}$ & LSE & $\boldsymbol{R}^{\mathbf{2}}$ \\
\hline Linear & 18310 & 0.376 & 60990 & 0.555 \\
\hline Logistic & 10847 & 0.630 & 32675 & 0.761 \\
\hline $\begin{array}{l}\text { Logarithm } \\
\text { ic }\end{array}$ & 14098 & 0.519 & 35281 & 0.742 \\
\hline $\begin{array}{l}\text { Plancks's } \\
\text { Law }\end{array}$ & 10326 & 0.648 & 49270 & 0.640 \\
\hline $\begin{array}{l}\text { Plancks's } \\
\text { Law Opt }\end{array}$ & 9652 & 0.671 & 32367 & 0.764 \\
\hline
\end{tabular}

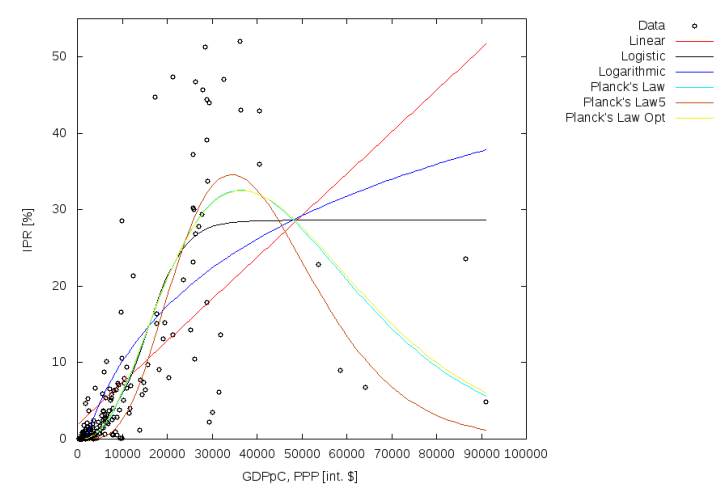

(a) 2000

Figure 3: Internet Penetration (IPR) as function of GDP per capita (GDPpC), Year 2000 (a) and 2010

(b)

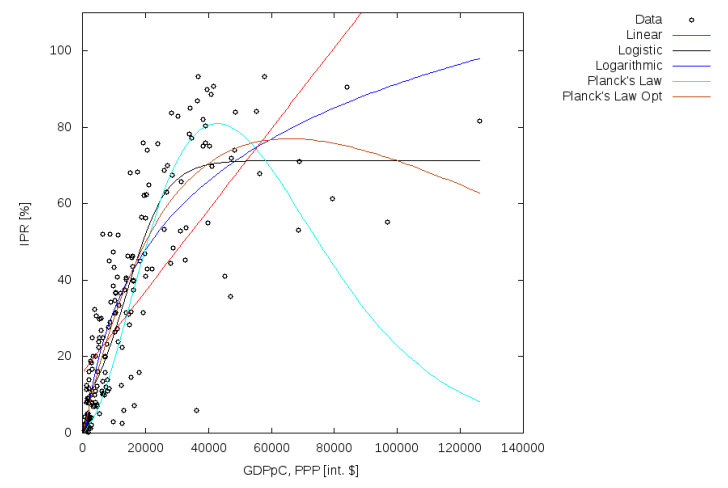

(b) 2010

Figure 3: Internet Penetration (IPR) as function of GDP per capita (GDPpC), Year 2000 (a) and 2010 (b)

Furthermore, a lot of countries with above-average value of GDP per capita have a below-average value of Internet penetration rate (Bahrain, Croatia, Gabon, Hungary, Kuwait, Saudi Arabia, Trinidad and Tobago, Qatar, Oman and Venezuela). The linear model fits the data not well, while the logarithmic regression function describes the relation between GDP per capita and Internet penetration rate slightly better than the linear regression. The logistic model is the second best out of the class of predefined models. 


\subsection{Economic Development and Education Level expressed via Adult Literacy}

Literacy is basic to build human capital and many governments in developed and developing countries invest financial capital to provide training that helps people to read and write and improves literacy rate. A primary interest is to seek for the worldwide relation between economical development and adult literacy rate of countries.

In principle the values for GDP per capita (GDPpC) and adult literacy rate (ALR) for the year 2000 have been discussed previously, however, the descriptive statistics for both variables is given in Table 11:

Table 11: Descriptive Statistics GDPpC and ALR 2000

\begin{tabular}{|l|l|l|l|l|l|l|}
\hline 2000 & N & Spread & Min & Max & Mean & Std \\
\hline GDPpC & 156 & 90741 & 271 & 91012 & 11381 & 14909 \\
\hline ALR & 156 & 90.25 & 9.54 & 99.79 & 81.13 & 21.37 \\
\hline
\end{tabular}

Saudi-Arabia and Oman are the only countries with above-average GDP per capita and simultaneously below-average adult literacy rate in 2000 . On the other side, there are 59 countries out of $156(38 \%)$ with below-average GDP per capita and aboveaverage adult literacy. This signals that high GDP per capita is not a main factor to have a high adult literacy rate, but a high value in GDP per capita is indeed an indication of high adult literacy.

Although the numbers for GDP per capita (GDPpC) and adult literacy rate (ALR) for the year 2010 have been reviewed before, the corresponding values for both variables are given in Table 12.

Table 12: Descriptive Statistics GDPpC and ALR 2010

\begin{tabular}{|l|l|l|l|l|l|l|}
\hline 2010 & N & $\begin{array}{l}\text { Sprea } \\
\text { d }\end{array}$ & Min & Max & Mean & Std \\
\hline GDPp & 15 & 125630 & 408 & $\begin{array}{l}12603 \\
8\end{array}$ & $\begin{array}{l}1748 \\
0\end{array}$ & $\begin{array}{l}199 \\
76\end{array}$ \\
\hline C & 6 & & & 99.92 & 85.15 & $\begin{array}{l}17 . \\
62\end{array}$ \\
\hline
\end{tabular}

Since enrollment in primary education in developing regions reached $90 \%$ in 2010, up from $82 \%$ in 2000 it is also laudable, that there is no country with above-average GDP per capita and concurrently below-average adult literacy rate. The mean value of $85 \%$ for adult literacy shows significant effects of national and international development programmes since 2000.

Figure 4 represents the relation between GDP per capita (GDPpc, PPP) and adult literacy rate (ALR) with scattered plots for year 2000 and 2010 and Table 13 gives the main values for the least square optimization. Despite the linear regression function delineates this relation in 2010 better than in 2000, it describes that relation not by any means well enough. The logistic function has the best _t to the data. But the logarithmic regression model shows the tendency of the relation between both factors generally, but since the adult literacy rate is limited to $100 \%$, the logistic function fits best to the data out of these three predefined functions.

Table 13: LSE and $\mathrm{R}^{2}$ for Regression ALR = $\mathrm{f}(\mathrm{GDPpC})$

\begin{tabular}{|l|l|l|l|l|}
\hline & \multicolumn{2}{|c|}{2000} & \multicolumn{2}{c|}{2010} \\
\hline & LSE & $\boldsymbol{R}^{\mathbf{2}}$ & LSE & $\boldsymbol{R}^{\mathbf{2}}$ \\
\hline Linear & 60421 & 0.146 & 37117 & 0.228 \\
\hline Logistic & 31959 & 0.548 & 18631 & 0.613 \\
\hline Logarithmic & 38736 & 0.453 & 21552 & 0.552 \\
\hline
\end{tabular}

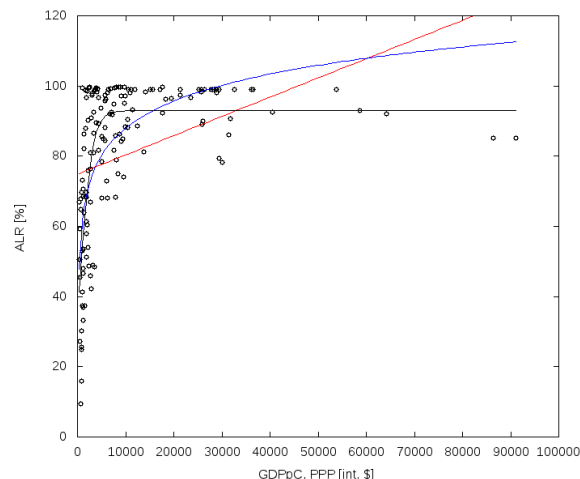

(a) 2000

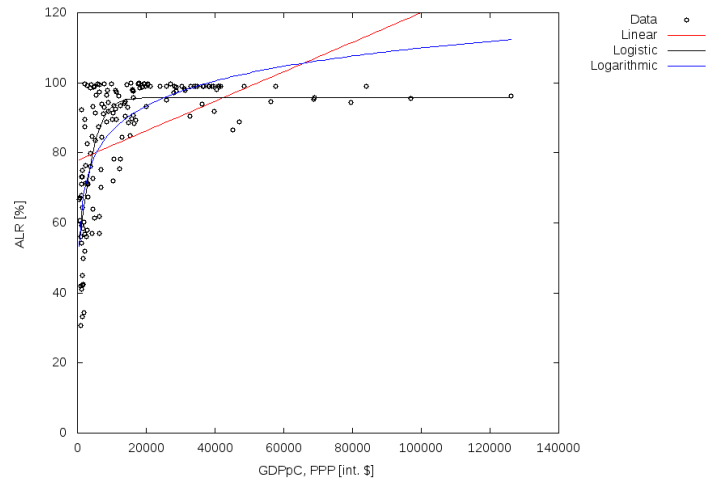

(b) 2010

Figure 4: Adult Literacy (ALR) as function of GDP per capita (GDPpC), Year 2000 (a) and 2010 (b)

\subsection{Economic Development and Education Level expressed via Education Index}

Again, the ability to read and write is the first step towards a high level of education, but it is apparent that the costs of investment for a long education are more than the investment costs for literacy only. 
Basically the statistical values for GDP per capita (GDPpC) and education index (EI) for the year 2000 and 2010 have been discussed above, but keep in mind the different amount of available data given here in Table 14 and Table 15. The states Gabon, Oman and Venezuela do not profit of their aboveaverage GDP per capita to perform also an aboveaverage value in education index.

Table 14: Descriptive Statistics GDPpC and EI 2000

\begin{tabular}{|l|l|l|l|l|l|l|}
\hline 2000 & N & Spread & Min & Max & Mean & Std \\
\hline GDPpC & 169 & 90741 & 271 & 91012 & 10840 & 14385 \\
\hline EI & 169 & 0.863 & 0.111 & 0.974 & 0.577 & 0.214 \\
\hline
\end{tabular}

Table 15: Descriptive Statistics GDPpC and EI 2010

\begin{tabular}{|l|l|l|l|l|}
\hline & \multicolumn{2}{|c|}{$\mathbf{2 0 0 0}$} & \multicolumn{2}{c|}{$\mathbf{2 0 1 0}$} \\
\hline & LSE & $\boldsymbol{R}^{\mathbf{2}}$ & LSE & $\boldsymbol{R}^{\mathbf{2}}$ \\
\hline Linear & 5.782 & 0.246 & 5.033 & 0.291 \\
\hline Logistic & 2.874 & 0.625 & 2.461 & 0.653 \\
\hline Logarithmic & 2.977 & 0.612 & 2.705 & 0.619 \\
\hline
\end{tabular}

Table 16: $\mathrm{LSE}$ and $\mathrm{R}^{2}$ for Regression $\mathrm{EI}=$ $\mathrm{f}(\mathrm{GDPpC})$

\begin{tabular}{|l|l|l|l|l|l|l|}
\hline 2010 & N & Spread & Min & Max & Mean & Std \\
\hline GDPpC & 176 & 125630 & 408 & 126038 & 16067 & 18288 \\
\hline EI & 176 & 0.822 & 0.177 & 0.99 & 0.648 & 0.200 \\
\hline
\end{tabular}

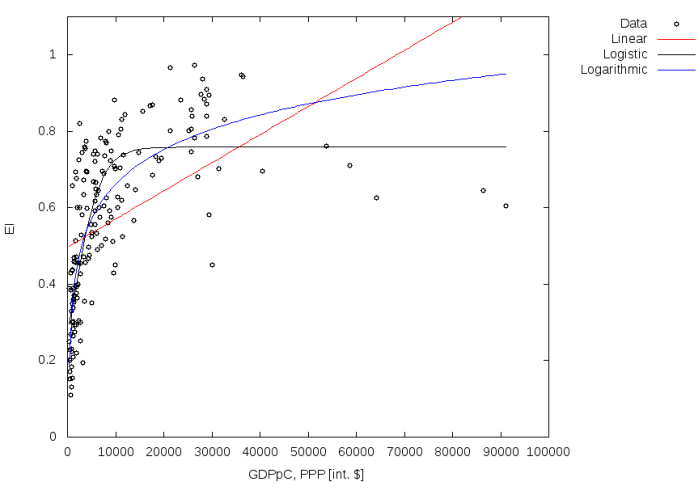

(a) 2000

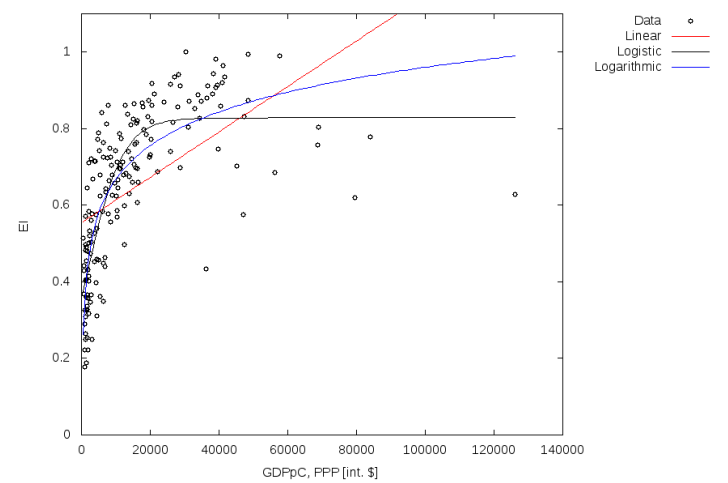

(b) 2010

Figure 5: Education Index (EI) as function of GDP per capita (GDPpC), Year 2000 (a) and 2010 (b)
Table 16 gives the values of least square error (LSE) and coefficient of determination $\left(\mathrm{R}^{2}\right)$ for year 2000 and 2010. The linear regression function fits the data for the relation between GDP per capita and education index not well in 2000, but for the year 2010 better than for year 2000. The logistic model explains this relation best out of the considered functions, as it is for adult literacy and GDP per capita. But compared to adult literacy rate the mean value of the education index is far away from a saturation value, which is theoretically at 1 .

Figure 5 shows the relation between both variables. Interesting is in 2010 compared to the year 2000 , that there are more countries with aboveaverage income level and simultaneously with below-average education index. These 'underperforming' countries are Equatorial Guinea, Kuwait, Oman, Qatar and Turkey. They performed well in economic development since 2000, but they could not reflect this to their educational development. But in fairness one should say, that the results of educational development occurs with a time lag.

\section{Multivariate Linear Regression to explain Internet Penetration}

So far we use only univariate linear and nonlinear regression analysis to explain the mutual relation between education level, average income level and Internet penetration rate of countries in the year 2000 and 2010. Now, this study will use multivariate regression analysis to explain the Internet penetration rate by the combination of average GDP per capita and education index as well as by the combination of average GDP per capita and adult literacy rate. Multivariate linear regression is a generalization of the basic linear regression model by considering more than one independent variable. Since non-linear regression functions are also used to model the relation between the education level and Internet in this study, it is necessary to rearrange the multivariate non-linear regression model for multivariate linear regression.

\subsection{Internet Penetration, GDP per capita and Adult Literacy Rate}

Looking to the Internet penetration rate (IPR) as the dependent variable and GDP per capita (GDPpC) and adult literacy rate (ALR) as the independent variables, we want to know, to which extent the average income level drives the Internet penetration rate relatively measured to the extent, that adult literacy drives the Internet penetration rate in a country, see equation 1 . A is the factor for average income, $\mathrm{B}$ the weight for adult literacy and $\mathrm{C}$ a constant variable. According to the previous 
findings, $f($ equation 5) and $g$ (equation 6) are the functions which _t best to the given data.

$$
\begin{gathered}
I P R=A \cdot f(G D P p C)+B \cdot g(A L R)+C=A \cdot G D P p C^{*}+B \cdot A L R^{*} \text { (1) } \\
G D P p C^{*}=f(G D P p C)=\frac{a \cdot G D P p C_{l}^{b}}{C \cdot \exp ^{A \cdot G D P I C-1}} \\
A L R^{*}=g(A L R)=a+b^{-\exp ^{(C \cdot A L R-a)}} \\
\Rightarrow \quad A=0.880, B=0.459, C=-2.343
\end{gathered}
$$

First, the factors $\mathrm{A}$ and $\mathrm{B}$ are positive, which means, that average income level and adult literacy rate impacts the Internet penetration rate positive. However, the result for the year 2000 shows, that GDP per capita has a weight of $65.7 \%$ and the adult literacy a weight of $34.3 \%$ regarding the contribution to Internet penetration. This means in plain, that GDP per capita impacts the Internet penetration twice more as the adult literacy rate impacts the Internet penetration.

Continuing in the same concept for the relation between Internet penetration rate, GDP per capita and adult literacy rate for the year 2010, the result for $\mathrm{A}, \mathrm{B}$ and $\mathrm{C}$ is as follows.

$$
A=0.806, B=0.425, C=-5.274
$$

Again the weight for $\mathrm{A}$ and $\mathrm{B}$ is positive in the year 2010. The GDP per capita contributes to Internet penetration rate with $65.4 \%$ and the adult literacy with $34.6 \%$. It should be noted, that the relatively contribution of GDP per capita and adult literacy rate to Internet penetration remains with the same weight in 2010 compared to the year 2000. One can say that GDP per capita is still that factor in 2010 , which is more important than the ability to read and write. Average income determines the ability to afford Internet connection. On the other hand, without the ability to read and write an Internet connection is nearly pointless. This is valid for year 2000 and for 2010.

\subsection{Internet Penetration, GDP per capita and Education Index}

The same multivariate regression analysis is done for the relation between Internet penetration rate, GDP per capita and education index for year 2000 and 2010. It is expected that the EI has to contribute anyway more to the Internet penetration rate as the adult literacy rate does. For year 2000 following coefficients are calculated.

$$
\begin{gathered}
I P R=A \cdot f(G D P p C)+B \cdot g(E I)+C=A \cdot G D P p C^{*}+B \cdot E I^{*}(4) \\
G D P p C^{*}=f(G D P p C)=\frac{a \cdot G D P p C_{1}^{\natural}}{\bar{c} \cdot \exp ^{A \cdot G D P C_{1-1}}}
\end{gathered}
$$

$$
\begin{aligned}
& E I^{*}=g(E I)=a+b \cdot \exp ^{(C \cdot E I-\alpha])} \\
& A=0.617, B=0.536, C=-1.040
\end{aligned}
$$

The factors A and B are positive, which means, that average income level and education index impacts the Internet penetration rate positive. The result shows, that GDP per capita impacts the Internet penetration rate with $53.5 \%$ and the education index with $46.5 \%$ in year 2000. Indeed, both independent variables have approximately the same weight of contribution to the Internet penetration rate. This result is not much surprising, due to the fact, that we expect a higher contribution of the education index to Internet penetration in comparison to the adult literacy rate. But a surprising fact is that the income level and education level are almost equivalently important for Internet penetration in 2000.

The multivariate regression analysis for the relation between the Internet penetration rate, average income level and education index in the year 2010 results following coefficients.

$$
A=0.669, B=0.440, C=-4.497
$$

The factors A and B are positive in the year 2010 again as it is for the year 2000. The result shows, that GDP per capita impacts the Internet penetration rate with $60.3 \%$ and the education index with $39.7 \%$. Now, compared to the year 2000, the education index has not approximately the same weight of contribution to the Internet penetration rate as the GDP per capita. One can argue, that GDP per capita still remains important, to be financially affordable to have Internet connection. But the education index measured as a weighted average of expected years of schooling and means years of schooling in a country, is not so important after a decade anymore as in the year 2000. This result is not much surprising, due to the fact, that technological development can eliminate somewhat the education level necessary for Internet usage.

\subsection{Multivariate Regression for Internet Penetration, GDP per capita, Adult Literacy and Education Index}

Looking to all variables together, i.e. the Internet penetration rate (IPR) as the dependent variable and the three variables GDP per capita (GDPpC), adult literacy rate (ALR) and education index (EI) as the independent variables, we want to know, to which extent the average income level, education index and adult literacy rate are driving the Internet penetration rate, see equation 7 . It is expected that the education index does contribute anyway more to the Internet penetration rate as the adult literacy rate does. A is the factor for average income, B the weight for 
education index, $\mathrm{C}$ the weight for adult literacy and $\mathrm{D}$ a constant variable.

$$
I P R=A \cdot f(G D P p C)+B \cdot g_{1}(E I)+C \cdot g_{2}(A L R)+D
$$

The analysis results in following coefficients for the year 2000.

$$
A=0.671, B=0.584, C=-0.239, D=-0.222
$$

It can be said, that average income and education index influence the Internet penetration positive, and somehow, the adult literacy a bit negative, but near at zero. If the same analysis is done for the relation between Internet penetration rate, GDP per capita, education index and adult literacy for the year 2010, following coefficients are the result.

$$
A=0.658, B=0.467, C=-0.016, D=-4.608
$$

The analysis for year 2010 shows, that average income level and education index still impact the Internet penetration most. The impact of the education index to Internet penetration is to a lesser extent in 2010 than in 2000. Indeed, in the year 2010, the weight for adult literacy rate is very close to zero now.

\subsection{Findings for Multivariate Regressions}

The multivariate analysis shows that Internet penetration rate is better explained by the combination of average GDP per capita and education index, than by either average GDP per capita or education index alone. The influence of both factors to Internet penetration is similar with some more power of the average GDP. The situation from 2000 and 2010 shows that average GDP even gains in importance. When comparing the impact of average GDP and adult literacy rate to Internet penetration rate, the influence of GDP per capita is almost double as the influence of adult literacy rate and the influence for average GDP remains essentially the same over time. This supports our expectations, that the education index tells more about having access to the Internet than does adult literacy rate. It is interesting, that the role of average GDP per capita even increases from 2000 to 2010 regarding the relation between Internet penetration, GDP per capita and education index, while remains the same for the relation between Internet penetration, GDP per capita and adult literacy. It might be that the growing Internet rates as well as the increase in adult literacy worldwide are reasons for that. Finally, the financial situation in terms of average income still defines strongly the limit of being able to join the Internet.

\section{Conclusion}

This study shows relations between education level expressed via adult literacy rate and education index and the Internet penetration rate with regression analysis of data from 2000 and 2010. First, it should be noted, that this analysis is of great intent, since the worldwide Internet penetration rate is about one-third, i.e. two-third of the world population has no access to the Internet. The analysis would reveal no relation between the education level of a country and the Internet penetration rate for a country.

The relation between education level and Internet penetration is modeled via linear and exponential regression functions. In general the exponential model fits the data well, while the linear model is less compatible, except for the relation between Internet penetration and education index in year 2010. There is a positive relation between education level in terms of adult literacy rate as well as education index and Internet penetration rate. The education index has a higher relation with the Internet penetration rate than the adult literacy rate. One reason for this is the higher relation of education index by means of school education years to monetary investments of states than the relation of adult literacy rate to money available and average income measured by GDP per capita. This has a consequence, that the relation between GDP per capita and education index is higher than the relation between GDP per capita and adult literacy rate, independent of whether these relations are modeled via linear, logarithmic and logistic functions, whereby the logistic model suits well compared to the other functions. So this study argues that policymakers need to promote comprehensive literacy education.

In general, Internet usage and penetration is a motivational and monetary issue. So far higher educated people are an indication for higher developed countries and for higher income countries, but the same is even more true for high average GDP per capita, which comes along with a higher Internet penetration rate as well as higher education levels.

The results of multivariate regression analysis show, that GDP per capita drives primarily the Internet penetration rate and even gains in importance regarding the multivariate regression between Internet penetration rate, GDP per capita and education index from 2000 through 2010. One can say in other words, that the education index became less important in relative terms. But the role of GDP per capita remains at the same level regarding the multivariate regression for Internet penetration, GDP per capita and adult literacy. Adult literacy rate essentially vanishes as an explaining factor, i.e. GDP per person and the education index carry principally all information concerning Internet 
penetration, that literacy rate could supply. The multivariate regression analysis argues similarly as the univariate regression that policymakers need to promote comprehensive literacy education.

Finally, this study concludes that the digital divide in terms of education level and economic development still is in place, but is declining, because more people worldwide use the Internet since 2000.The growth in Internet penetration occurs in developed and developing countries, although developing countries reached almost saturation. The results show a high digital inequality resulting from different education levels and income situations. Policymakers should rather encourage investments into (digital) literacy than into higher education if the aim is to increase the internet penetration rate.

\section{References}

[1] Internet Penetration and its Correlation to Gross Domestic Product: An Analysis of the Nordic Countries. International Journal of Business, Humanities and Technology. Vol. 3 No. 2; February 2013.

[2] The diffusion of the Internet: A cross-country analysis. Telecommunication Policy, 34, pp. 323-340. 2010.

[3] Factors contribution to global digital divide: Some empirical results. Journal of Global Information Technology Management 8, pp. 47-65. 2005.

[4] The Internet and Knowledge Gaps: A Theoretical and Empirical Investigation. European Journal of Communication Vol. 17 (1), pp. 65-84. 2002.

[5] The determinants of the global digital devide: A crosscountry analysis of computer and Internet penetration. in: Oxford Economic Papers 59, 2007, 16-44, doi:10.1093/oep/gpl024.

[6] Brooding the Year 2000 Millenium Bug. Spectrum IEEE, Vol. 35 Issue 6, pp. 68-73. doi: 10.1109/6.681974

[7] Von QWERTY zu WYSIWYG - Texte, Tastatur, Papier. in: Sprache im technischen Zeitalter, June 1987, pp. 136-144.

[8] The Rise of Big Data. How It's Changing the Way We Think About the World. Council on Foreign Affairs. http://www.foreignaffairs.com/articles/139104/kenneth neil-cukier-and-viktor-mayer-schoenberger/the-rise-of-bigdata

[9] Digital Divide Research. Achievements and Shortcomings. Poetics 34 (2006), pp. 221-235.

[10] The Network Society, Third Edition. London, Thousand Oaks CA, New Delhi, Singapore: Sage Publications. 2012

[11] . The Evolution of the Digital Devide. The Digital Devide turns to Inequality of
Skills and Usage. Digital Enlightenment Yearbook 2012. J. Bus et al. (eds.). IOS Press. 2012. doi:10.3233/978-161499-057-4-57.

[12] Forum Info 2000. Forum Informationsgesellschaft der Bundesregierung: Herausforderungen 2025. Auf dem Weg in eine nachhaltige Informationsgesellschaft. Hrsg. FAW, Ulm. 1998

[13] Statistics. W. W. Norton \& Company. 4th edition 2007. ISBN 978-0393929720

[14] The Role of Income Inequality in a Multivariate Cross-National Analysis of the Digital Divide. Social Science Computer Review Vol. 27 (1), Feb. 2009, pp. 4158.

[15] Weaving the Western Web: Explaining differences in Internet connectivity among OECD countries. Telecommunication Policy 23. pp. 701-718. 1999.

[16] Human Development Report. The Rise of the South. Human Progress in a Diverse World. United Nations Development Programme. 2013. ISBN 978-92-1-126340-4

[17] International Telecommunication Union. Open Systems Interconnection - Model and Notation.

ISO/IEC

7498-1:1994,

http://handle.itu.int/11.1002/1000/2820.

[18] International Telecommunication Union. Measuring the Information Society.ISBN 978-92-61-14071-7, p. 2.

[19] International Telecommunication Union. Statistics. http://www.itu.int/en/ITU-D/Statistics/Pages/stat/ default.aspx. 2013

[20] Income Modeling and Balancing - a rigorous treatment of distribution patterns'. Book Manuscript, Ulm, 2014.

[21] Cross-country Diffusion of the Internet. Information Economics and Policy 14. pp. 297-310. 2002.

[22] Comparison of Old and New Methodology in Human Development and Poverty Indexes:

A Case of the Least Developed Countries. International Business Information Management Association (IBIMA). Journal of Economic Studies and Research Vol. 2012. doi: $10.5171 / 2012.290025$.

[23] Cramming more components onto integrated circuits. in: Electronics, Vol. 38, No. 8, April 1965.

[24] Technological Convergence. in: Science Journal of Physics, Volume 2012, Article ID sjp-221, 5 Pages, 2012. doi: $10.7237 / \mathrm{sjp} / 221$.

[25] IT employment prospects: beyond the dotcom bubble. European Journal of Information

Systems (2008) 17, pp. 182?197. doi:10.1057/ejis.2008.19

[26] Mathematical contributions to the theory of evolution. III. Regressions, heredity, and panmixia. Philosophical Transactions of the Royal Society Ser. A187: pp. 253-318 
[27] Notes on history of correlation. Biometrika 13: pp. $25-45$.

[28] Using the technology acceptance model to explain how attitudes determine Internet

usage: The role of perceived access barriers and demographics. Journal of Business Research 59 (2006).

[29] Relation and Growth of Internet Penetration Rate with Human Development

Level from 2000 to 2010. International Business Information Management Association (IBIMA).

Communications of IBIMA Vol. 2012. doi:10.5171/2012.778309.

[30] Digital Divide: Determinants and policies with special reference to Asia. Journal of Asian Economics 13. pp. 811-825. 20003.

[31] Globalisation and Information Technology. Bartosch, U./Wagner, J. (ed.). in: International Conference in celebration of the 85th birthday of Carl-Friedrich von Weizsäcker, Evangelical Academy Tutzing, 1997, pp. 105107.

[32] The European Way to the Global Information Society. IPTS Report, No. 32, pp. 10-16, 1999.

[33] Die Zukunft der Infrastrukturen - Intelligente Netzwerke für eine Nachhaltige Entwicklung. in: Metropolis-Verl., ISBN: 3895185027, 2005, pp. 97112.

[34] ICT and the possibilities of leapfrogging by developing countries. in: International

Labour Review, 140, pp. 193-210.

[35] Reconceptualising time and space in the era of electronic media and communications in: Journal of Media and Communications, Vol. 1, July 2009: 11-32: ISSN: 1836-5132.

[36] Adult and Youth Literacy, 1990-2015. Analysis of data for 41 selected countries. UNESCO Institute for Statistics. 2012. ISBN 978-92-9189-117-7

[37] United Nations Educational Scientific and Cultural Organization, International Telecommunications Union (2013). Technology, Broadband and Education. Advancing the Education for All Agenda. A Report by the Broadband Commission Working Group on Education, 2013.

[38] UNESCO Institute for Statistics.

http://www.uis.unesco.org/Pages/default.aspx

[39] Getting Prepared for a globalised digital world. European Institute of Innovation and Technology (ed.) in: Annual Innovation Forum, Brussels, 2013, pp. 2027.

[40] Mobile Money Webinar. http://www.vodafone.com/ content/dam/vodafone/investors/company_presentations/ 2013/Mobile_Money_Webinar_transcript.pdf
[41] World Bank. World Data Bank. http://databank.worldbank.org/data/home.aspx

[42] World Summit on the Information Society. United Nations and International Telecommunication Union.

Geneva 2003. http://www.itu.int/dms_pub/itus/md/03/wsis/doc/S03-WSIS-DOC-0004!!PDF-E.pdf

[43] World Summit on the Information Society. United Nations and International Telecommunication Union. Tunis 2005. http://www.itu.int/wsis/docs2/tunis/ off/6rev1.html

[44] World Summit on Sustainable Development. United Nations. Johannesburg 2002. http:// www.un.org/ events/wssd

[45] Income Disparity and Digital Divide: The Internet Consumption Model and cross-country empirical research. Telecommunication Policy 37. 2013. pp. 515-529. 